University of Rhode Island

DigitalCommons@URI

\title{
Age-specific trends in health-related quality of life among US adults: Findings from National Health and Nutrition Examination Survey, 2001-2016
}

Mary L. Greaney

University of Rhode Island, mgreaney@uri.edu

Steven Cohen

University of Rhode Island, steven_cohen@uri.edu

Bryan J. Blissmer

University of Rhode Island, bblissme@uri.edu

Jacob E. Earp

University of Rhode Island, jacob_earp@uri.edu

Eollow this and additional works at: https://digitalcommons.uri.edu/htl_facpubs

The University of Rhode Island Faculty have made this article openly available.

Please let us know how Open Access to this research benefits you.

This is a pre-publication author manuscript of the final, published article.

Terms of Use

This article is made available under the terms and conditions applicable towards Open Access

Policy Articles, as set forth in our Terms of Use.

Citation/Publisher Attribution

Greaney, M.L., Cohen, S.A., Blissmer, B.J. et al. Age-specific trends in health-related quality of life among US adults: findings from National Health and Nutrition Examination Survey, 2001-2016. Qual Life Res 28, 3249-3257 (2019). https://doi.org/10.1007/s11136-019-02280-z

This Article is brought to you for free and open access by the Health Studies at DigitalCommons@URI. It has been accepted for inclusion in Health Studies Faculty Publications by an authorized administrator of DigitalCommons@URI. For more information, please contact digitalcommons-group@uri.edu. 


\section{Age-specific trends in health-related quality of life among US adults: Findings from National Health and Nutrition Examination Survey, 2001-2016}

Mary L. Greaney, PhD, Steven A. Cohen, DrPH, Bryan J. Blissmer, PhD, Jacob E. Earp, PhD, \& Furong $\mathrm{Xu}, \mathrm{PhD}^{2}$

Mary L. Greaney, PhD (corresponding author)

Health Studies

University of Rhode Island

25 West Independence Way

Kingston, RI 02881

Email:mgreaney@uri.edu

Steven A. Cohen, DrPH

Health Studies

University of Rhode Island

25 West Independence Way

Kingston, RI 02881

Bryan J. Blissmer, PhD

Institute for Integrated Health and Innovation

130 Flagg Rd

Kingston, RI 02881

Jacob E. Earp, PhD

Department of Kinesiology

University of Rhode Island

25 West Independence Way

Kingston, RI 02881

Furong $\mathrm{Xu}, \mathrm{PhD}$

Department of Kinesiology

University of Rhode Island

25 West Independence Way

Kingston, RI 02881 


\begin{abstract}
Purpose: Health-related quality of life (HRQoL) is an important indicator of population health, yet no age-specific trend analyses in HRQoL have been conducted with a nationally representative sample since 2004. Therefore, to address this gap, an age-specific trend analysis of HRQoL was conducted using National Health and Nutrition Examination Surveys (NHANES) data.
\end{abstract}

Methods: NHANES 2001-2016 data (8 cycles) were examined to evaluate trends in HRQoL by age group (young adults: 21-39, middle-aged: 40-64, older adults: 65+). HRQoL was assessed by self-reported health (SRH) and number of physically unhealthy, mentally unhealthy, and inactive days to due to physical or mental health in the past 30 days. Multiple linear or logistic regression analyses explored trends in HRQoL by age group, adjusting for demographics over time.

Results: Analysis revealed increasing fair/poor SRH over time for the entire sample $(\beta=0.34$, 95\%CI: 0.08, 0.60, p=0.011). However, age-specific analysis identified a bi-annual increase in fair/poor SRH only among young adults $(\beta=0.49,95 \% \mathrm{CI}: 0.22,0.76, \mathrm{p}<0.001)$ and a decrease among older adults $(\beta=-0.60,95 \% \mathrm{CI}:-1.14,-0.06, \mathrm{p}=0.03)$. Closer inspection revealed increasing fair/poor SRH increased among young women $(\beta=0.52,95 \% \mathrm{CI}: 0.11,0.93, \mathrm{p}=0.013)$ and young men $(\beta=0.46,95 \% \mathrm{CI}: 0.04,0.88, \mathrm{p}=0.03)$ but decreased among older women $(\beta=-$ $0.81,95 \% \mathrm{CI}:-1.59,-0.03, \mathrm{p}=0.042$ ) over time. Analyses also determined that there was a trend for a decreasing number of physically unhealthy days among young adults $(\mathrm{p}<0.001)$, although no trends were observed for the other HRQoL items.

Conclusions: Although there was a significant trend over time for increasing fair/poor SRH when considering the entire sample, this trend was not consistent between age groups or sexes. 
Given increasing fair/poor SRH among young adults there is a need to understand and address factors relating to HRQoL among this age group.

Key words: health-related quality of life, aging, trend analysis, NHANES 


\section{Background}

Health-related quality of life (HRQoL) encompasses one's physical health, mental health, and social well-being [1]. Better HRQoL is associated with lower utilization of outpatient services and hospitalization rates [2,3], and is an important population health indicator due to its relationship with multimorbidity in adults [4] and mortality in older adults [5,6].

HRQoL is often assessed by self-reported health status (SRH) or by individuals reporting the number of physically unhealthy days, mentally unhealthy days, and/or inactive days due to physical or mental health in the past 30 days [7-11]. The most recent literature on this topic indicates that there is an increasing number of adults who report fair/poor SRH and that there also is an increase in the number of physically unhealthy, mentally unhealthy, and inactive days due to physical or mental health in the past 30 days among adults [7-10]. However, to our knowledge, the last age-specific trend analysis of HRQoL with nationally representative data was conducted in 2004 using the Behavioral Risk Factors Surveillance System (BRFSS) data collected between 1993 and 2001 [8]. In that study, researchers identified a 1.2\% average annual increase of in fair/poor SRH and about a $2 \%$ increase in the number of physically unhealthy days, mentally unhealthy days, and inactive days due to physical or mental health [8].

Furthermore, this analysis determined that although HRQoL declined in most age groups it did not change significantly among older adults [8]. More recent research has identified differences in HRQoL by age $[11,12]$. For example, analyses of data from the 2006 and 2010 BRFSS determined that a higher percentage of older adults (65+ years) reported fair/poor SRH than adults in other age groups [11]. Similarly, analysis of data from two cycles of data from the National Epidemiologic Surveys on Alcohol and Related Conditions found that HRQoL 
decreased from 2001-02 to 2012-13 and that the decline was greater among young and middleaged adults than older adults (aged $\geq 55$ ) [12].

Nonetheless, despite the importance of HRQoL and noted differences in HRQoL by age in previous studies $[8,11,12]$, no age-sex specific HRQoL trend analyses have been conducted using a nationally representative sample since 2004 [8]. There is a need to address this research gap. Determining if differences exist in HRQoL by sex-specific age groups in a nationally representative sample will allow for potential identification of changes in HRQoL in these subgroups that could be masked if the sample is only examined in its entirety. Given that earlier studies have identified changes in HRQoL over time $[8,12]$ and changes in family structure/living situations, technology use, etc. $[13,14]$, it is conceivable that there have been changes in HRQoL. Therefore, the purpose of this study was to address this gap and investigate age-sex specific HRQoL trends among adults from 2001 to 2016 in a nationally representative sample.

\section{Methods}

This study was a cross-sectional data analysis of eight cycles of de-identified data from the National Health and Nutrition and Examination Survey (NHANES). The data were collected from 2001 to 2016, and made available by the Centers for Disease Control and Prevention (CDC) website $[15,16]$. NHANES has surveyed a nationally representative sample of the noninstitutionalized US civilian population in 2-year cycles since 1999 [16]. Every NHANES cycle includes a unique sample as respondents are not followed over time. Each year recruitment takes place in 15 US counties, with households being selected for recruitment. NHANES interviewers visit each household to ask for the age, race/ethnicity, and sex of all members of the household 
[16]. A computer algorithm then selects all, some, or none of the household members to participate in the voluntary NHANES assessment [16]. The NHANES assessment includes a household interview and a physical examination conducted in a mobile examination center [16]. The response rate for the survey ranges from $46.5 \%$ to $84.0 \%$ [16].

The analytic sample for the current study was limited to adults $21+$ years of age who completed the examined HRQoL items. Of the 92,097 NHANES respondents assessed from 2001 to $2016,41,625$ were 21 years or older at the time of examination and had completed the HRQoL items. Since the current study used de-identified data from existing publicly accessible data set, the University of Rhode Island's Institutional Review Board determined that this study does not meet the definition of human subject research based on federal regulation 45 CFR 46 .

\section{$\underline{\text { Measures }}$}

HRQoL was assessed by the CDC's 4-item set of Healthy Days core question, which includes: 1) SRH, 2) number of physically unhealthy days, 3) number of mentally unhealthy days, and 4) number of inactive days due to physical or mental health in the past 30 days (referred to as inactive days from henceforth) $[1,15]$. SRH was assessed by a single item that asked respondents to rate their health using one the following response options: fair, poor, good, very good, and excellent [15]. For descriptive purposes, and as is frequently done, SRH was dichotomized into two categories (fair/poor, good/very good/excellent) as this grouping increase the ease of interpreting SRH as one category implies less than satisfactory health and the other category is indicative of better perceived health.

Respondents also completed three additional HRQoL items [15]. The first item assessed number of physically unhealthy days: "Now thinking about your physical health, which includes physical illness and injury, for how many days during the past 30 days was your physical health 
not good?" The second item assessed mentally unhealthy days: "Now thinking about your mental health, which includes stress, depression, and problems with emotions, for how many days during the past 30 days was your mental health not good?" The third, and last item, assessed number of inactive days due to physical or mental health in the past 30 days (referred to as inactive days from henceforth): "During the past 30 days, for about how many days did poor physical or mental health keep you from doing your usual activities, such as self-care, work, or recreation?" For these three items, respondents could respond 0-30 days. After NHANES 201112, HRQoL was assessed by SRH only. Each HRQoL item was examined independently.

Demographic characteristic examined were age, sex (male, female), race/ethnicity (nonHispanic white, non-Hispanic black, Mexican American, others), education (high school graduate or less, college or above). Respondents were categorized into three age groups: young adults (21-39), middle-aged adults (40-64), and older adults (65+). The poverty-to-income ratio was calculated using reported family income and size, which were used to determine if respondent's income was at or above $(\geq 1)$ or below the poverty line $(<1)[17]$.

\section{$\underline{\text { Data Analyses }}$}

All analyses used the sample weights suggested by the CDC's National Center for Health Statistics [18]. A sample weight is a weight that is assigned to each survey respondent, and it is a measure of the number of people in the population represented by that respondent. When unequal selection probability is applied, as in the NHANES sample, sample weights are used to produce an unbiased national estimate $[16,18]$. The descriptive results for continuous variables were presented using weighted means \pm standard errors and categorical variables were presented using counts and weighted percentages. 
The weighted biennial prevalence and corresponding estimated 95\% confidence intervals (CI) for SRH and the weighted mean $(95 \% \mathrm{CI})$ for the HRQoL day items (number of physical unhealthy days, mentally unhealthy days and inactive days in the prior 30 days) were calculated by age group. The unadjusted p-values for linear time trends were calculated using univariable logistic regression for the prevalence of fair/poor SRH (versus good/very good/excellent SRH). Linear regression models also were constructed to examine linear trends for each of the day measures and to determine the unadjusted p-values. The linear time trends analyses used surveyed year as a single continuous independent variable in all models. Time trends were plotted using linear best-fit plots based on the weighted prevalence for SRH and mean for the other HRQoL variables over surveyed years, stratified by age group and sex.

For the multivariable analyses, the adjusted average biennial (every two years) change (95\% CI) for each of the HRQoL items was estimated. Multiple linear regression models were constructed to examine the continuous HRQoL items (number of physically unhealthy days, number of mentally unhealthy days, and number of inactive days) and logistic regression models examined the binary variable (fair/poor versus good/very good/excellent SRH) were construed to examine differences in HRQoL by age group (young, middle-aged, and older). In these models, the year was treated as continuous variable. The interaction term, age multiplied by the surveyed year, was then added to the models as the independent variable to examine the potential interaction between age and time and to investigate whether changes over time in the examined HRQoL items differed by age group. The models were then adjusted for covariates (age, sex, race/ethnicity, education, and poverty level). Model fit was tested using the Hosmer-Lemeshow test with a $\mathrm{p}$-value above alpha $=0.05$ being viewed as being indicative of a model appropriately fitting the data. Similar analyses examined difference in HRQoL by sex by age group. All 
analyses were conducted using SAS version 9.4 (SAS Institute Inc., Cary, NC, USA), and p < 0.05 was considered to represent statistical significance.

\section{Results}

The analytic sample was $52 \%$ female and with $31.3 \%$ identifying as racial/ethnic minorities. In addition, $40.9 \%$ of the sample had a high school degree or less and $13.9 \%$ were living below the poverty line. In total, $17.3 \%$ of respondents reported fair/poor SRH, and the sample reported an average of $3.5 \pm 0.1$ physically unhealthy days, $3.8 \pm 0.1$ mentally unhealthy days, and 1.7 \pm 0.1 inactive days in the prior 30 days (see Table 1).

In the unadjusted trend analysis (see Table 2), there was no significant overall time trend for any of the HRQoL items, although the age-specific analysis revealed a biennial increase in fair/poor SRH for young adults (aged 21-39, p=0.012) and decrease among older respondents (aged $65+, \mathrm{p}=0.015)$. Additionally, there was a trend for a decreasing number of physically unhealthy days among young adults $(\mathrm{p}<0.001)$. When models were stratified by sex, the analyses revealed a biennial increase in fair/poor SRH among young women $(\mathrm{p}=0.026)$ and middle-aged men (aged 40-64, p=0.040) and a trend for decreasing fair/poor SRH among older women (aged $65+, p=0.021)$. Furthermore, young men $(p=0.019)$ and young women $(p=0.006)$ had a reduced mean number of physically unhealthy days over time,

[Insert Tables 1 and 2 about here.]

As shown in Table 3 and Figure 1, there was a significant increasing trend in fair/poor SRH observed for the entire sample in the adjusted models, at an average biennial rate increase of $0.34 \%(\beta=0.34,95 \% \mathrm{CI}: 0.08,0.60, \mathrm{p}=0.011)$. No other time trends were identified for the entire sample. 
[Insert Figure 1 about here.]

The age-specific analysis revealed a significant increase over time in fair/poor SRH for young adults $(\beta=0.49,95 \% \mathrm{CI}: 0.22,0.76, \mathrm{p}<0.001)$ and decrease for older adults $(\beta=-0.60$, 95\%CI: $-1.14,-0.06, \mathrm{p}=0.03)$.

Additionally, there was a significant biennial decrease in the number of physical unhealthy days for young adults $(\beta=-0.14,95 \% \mathrm{CI}:-0.22,-0.06, \mathrm{p}<0.001)$. Moreover, as seen in Table 3, older adults had a greater reduction in fair/poor SRH ( $\beta=-1.03,95 \%$ CI: $-1.63,-0.43)$, smaller decrease in number of physical unhealthy days ( $\beta=0.09,95 \%$ CI: $0.01,0.17)$ and mentally unhealthy days ( $\beta=-0.10,95 \% \mathrm{CI}$ : $-0.19,-0.01)$ as well as a greater increase in inactive days ( $\beta=0.12,95 \% \mathrm{CI}: 0.01,0.23)$ than young adults over time. Similar differences were observed between middle-aged and young adults (see Table 3 ).

The adjusted sex stratified analyses (see Table 3), identified a significant bi-annual increase in fair/poor SRH ( $\beta=0.52,95 \% \mathrm{CI}: 0.11,0.93, \mathrm{p}=0.013)$ and a decrease in the mean number of physical unhealthy days ( $\beta=-0.18,95 \% \mathrm{CI}:-0.30,-0.07, \mathrm{p}=0.002)$ among young women. Additionally, a biennial increase fair/poor SRH was identified among young men $(\beta=0.46,95 \%$ CI: $0.04,0.88, p=0.03)$ and there was a decrease in fair/poor SRH among older women $(\beta=-0.81,95 \% \mathrm{CI}:-1.59,-0.03, \mathrm{p}=0.04)$. There was a difference between older women and young women in the observed temporal rate of change in fair/poor SRH ( $\beta=-1.20,95 \% \mathrm{CI}$ : $2.01,-0.40$ ), physical unhealthy days ( $\beta=0.06,95 \% \mathrm{CI}: 0.00,0.12)$, mentally unhealthy days ( $\beta=-$ $0.18,95 \%$ CI: $-0.33,-0.03)$, and inactive days $(\beta=0.11,95 \% \mathrm{CI}$ : $0.01,0.21)$. There also was a difference between middle-aged and young women in the temporal rate of change in fair/poor SRH ( $\beta=-0.27,95 \%$ CI: $-0.53,-0.01)$, physical unhealthy days ( $\beta=0.12,95 \%$ CI: $0.01,0.23)$, and 
inactive days ( $\beta=0.08,95 \%$ CI: $0.00,0.16)$. Similar results were observed among men (see Table $3)$.

\section{Discussion}

The current study was conducted to address a need for a recent age-specific HRQoL trend analysis in a large representative sample of US adults. Differences in the change rate were identified for all examined HRQoL items (SRH, number of physical unhealthy days, mentally unhealthy days, and inactive days in the prior 30 days). A notable finding of the present study was that although there was a significant trend for increasing fair/poor SRH between 2001 and 2016 among entire sample, this trend was not consistent across age groups. Specifically, the increase in fair/poor SRH occurred only among young adults (aged 21-39) and while there was a decrease in fair/poor SRH over time among older adults (aged 65+) and no significant change in SRH among middle-aged adults (aged 40-64). These trends are similar to those previously identified $[6,8,9,11,19]$ and indicate that fair/poor SRH continues to increase among young adults while declining among older adults. Taken together these results suggest an increasing need for targeted policy changes, interventions and services that may improve HRQoL in young or middle-aged adults.

Despite the trend for worsening SRH in young adults (aged 21-39) observed in this study, this age group reported fewer physically unhealthy days and no change in mentally unhealthy days, and inactive days in the prior 30 days, which contrasts with prior studies [8-11]. Further study is warranted to understand why perceptions of SRH are decreasing in this population. Zack and colleagues (2004) analysis of 1993 and 2001 BRFSS data determined that fair/poor SRH increased among young adults (aged 18-44) as was found in the present study; however, they 
also identified an increase number of physical unhealthy days, mentally unhealthy days, and inactive days among this age group, which the current study did not [8]. Another analysis of BRFSS data $(2006,2010)$ found that fair/poor SRH remained stable in the two youngest age groups (ages 18-24, ages 25-34) while the number of physically unhealthy days increased for adults aged 25-34, and number of mentally unhealthy days increased among aged 35-44 [11]. Nonetheless, direct comparisons between the current study and these two analyses of BRFSS data should be made with caution due to different data sources and study design, including different age groupings and different number of data points $(2$ used in previous studies and 8 used in the current study) [11].

The current study and previous studies have found that a greater percentage of older adults than young and middle-aged adults report fair/poor SRH [8,11]. However, a noteworthy observation of the present study was that in the most recent 2015-2016 NHANES data revealed that the percent of older adults reporting fair/poor SRH (19.2\%) was slightly lower than that reported in the middle-aged group (19.6\%). This observation provides support for targeted interventions designed to address SRH in younger populations, but also suggest that the research into the underlying cause of the improvements in SRH in older adults as this may provide insights into what types of changes may be effective for their younger counterparts.

In addition to difference in HRQoL by age, the current study also identified differences in HRQoL by sex. Among young men and young women there was an increase in fair/poor SRH, with the greatest increase being among young women. Moreover, there was decrease in the number of physically unhealthy days among young women but not young men. The current study builds on earlier research that documented an increase among men and women in fair/poor SRH, number of physically unhealthy days, mentally unhealthy days, and inactive days (1993- 
2001, 9 data points) [8] but prior research did not explore percentage change over time by sex by age as was done in the current study. Determining changes in HRQoL by sex-specific age groups is important as it will identify potential subgroups with declining HRQoL that may be masked if the sample is only examined in its entirety. A minimal clinically important difference approach suggests that a 0.5 -point change in a 7-point HRQoL is indicative of a small but important difference in HRQoL [20, 21]. However, we cannot compare results to the current study to this due to the use different HRQoL instrument. Nonetheless, differences in HRQoL have been identified by diabetes status [22], metabolic syndrome [23], chronic obstructive pulmonary disease [24], physical activity [25] and weight status [26], which suggests monitoring and addressing changes in HRQoL is important.

Study findings should be considered in regards to study limitations that includes the cross-sectional study design that does not allow causality to be determined, the use of selfreported measures, and that some of the HRQoL measures were only available up to 2012. In addition, multiple models were constructed, but analyses were not adjusted for multiple tests, although the approach used in this study is commonly used in the biomedical literature [27]. Lastly, we are unable to determine if the magnitude of the identified changes in the HRQoL measures are clinically relevant, as only limited studies have examined change in these items at the individual level [1]. However, we feel given the magnitude of the observed change in HRQoL items and that changes in SRH are associated with morbidity and/or mortality $[2,28]$ that the observed changes are likely clinically relevant. Nonetheless, monitoring population trends in HRQoL is important for determining progress on achieving the Healthy People 2020 goal to "Improve health-related quality of life and well-being for all individuals" [29]. Study strengths include the use of NHANES data collected over a 16-year period for the SRH measure 
and over a 12-year period for the number of physically unhealthy days, number of mentally unhealthy days, and number of inactive days. Importantly, this is the first study, to our knowledge to use of data from multiple NHANES cycles to examine age-sex specific HRQoL trend in adults since 2001 .

\section{Conclusions}

The present analysis of HRQoL revealed that between 2001-2016, the prevalence of fair/poor SRH increased among young adult respondents (aged 21-39) and decreased among older adults (age 65+). If this trend continues older adults will have a lower percentage reporting fair/poor SRH than the overall population in three to four years. Additionally, the currently study determined that between 2001 and 2012 the mean number of physical unhealthy days in the previous 30 days declined for young adults with the greatest decrease occurring among young women. The number of mental unhealthy days and inactive days in the previous 30 days was relatively constant throughout over the 12 years that this indicator was assessed, although the rate of change did differ between age groups. Given that HRQoL is an important indicator of multimorbidity in adults [4] and mortality in older adults $[5,6]$ effort needs to be made to understand and address differences in HRQoL by sex and age groups.

\section{List of abbreviations}

HRQOL: Health-related quality of life

SRH: Self-reported health

NHANES: National Health and Nutrition Examination Survey

BRFSS: Behavioral Risk Factors Surveillance System

CI: Confidence interval 


\section{Compliance with Ethical Standards:}

Conflict of Interest: Dr. Greaney declares that she has no conflict of interest. Dr. Xu declares

that she has no conflict of interest. Dr. Cohen declares that he has no conflict of interest. Dr. Earp declares that he has no conflict of interest. Dr. Blissmer declares that he has no conflict of interest.

Ethical approval: This article does not contain any studies with human participants performed by any of the authors. 


\section{References}

1. Moriarty, D. G., Zack, M. M., \& Kobau, R. (2003). The Centers for Disease Control and Prevention's Healthy Days Measures - Population tracking of perceived physical and mental health over time. Health and Quality of Life Outcomes, 1, 37. doi: 10.1186/1477$7525-1-37$

2. DeSalvo, K. B., Fan, V. S., McDonell, M. B., \& Fihn, S. D. (2005). Predicting mortality and healthcare utilization with a single question. Health Serv Res, 40, 1234-46.

3. Miilunpalo, S., Vuori, I., Oja, P., Pasanen, M., \&Urponen, H. (1997). Self-rated health status as a health measure: the predictive value of self-reported health status on the use of physician services and on mortality in the working-age population. J Clin Epidemiol, 50, $517-28$.

4. Wang, L., Palmer, A. J., Cocker, F., \& Sanderson, K. (2017). Multimorbidity and healthrelated quality of life (HRQOL) in a nationally representative population sample: implications of count versus cluster method for defining multimorbidity on HRQOL. Health and Quality of Life Outcomes, 15(1), 7. doi: 10.1186/s12955-016-0580-x.

5. Jia, H., Muennig, P., Lubetkin, E., \& Gold, M. (2004). Predicting geographical variations in behavioural risk factors: An analysis of physical and mental healthy days. J Epidemiol Community Health, 58(2), 150-155.

6. Idler, E. L., \& Benyamini, Y. (1997). Self-rated health and mortality: A review of twenty-seven community studies. J Health Soc Behav, 28(1), 21-37.

7. Zahran, H. S., Kobau, R., Moriarty, D. G., Zack, M. M., Holt, J., Donehoo, R. (2005). Health-related quality of life surveillance--United States, 1993-2002. MMWR Surveill Summ, 54(4), 1-35. 
8. Zack, M. M., Moriarty, D. G., Stroup, D. F., Ford, E. S., \& Mokdad, A. H. (2004). Worsening trends in adult health-related quality of life and self-related health---United States, 1993--2001. Public Health Rep, 119, 493-505.

9. Centers for Disease Control and Prevention. (2004). Self-reported frequent mental distress among adults-United States, 1993-2001. MMWR Morb Mortal Wkly Rep, 53, 963-966.

10. Dwyer-Lindgren, L., Mackenbach, J. P., van Lenthe, F. J., \& Mokdad, A. H. (2017). Selfreported general health, physical distress, mental distress, and activity limitation by US county, 1995-2012. Population Health Metrics, 15, 16. doi: 10.1186/s12963-017-0133-5

11. Zack, M. M. (2013). Health-related quality of life-United States, 2006 and 2010. MMWR Surveill. Summ, 62 (3), 105-111.

12. Olfson, M., Wall, M., Liu, S. M., Schoenbaum, M., \& Blanco C. (2017). Declining health-related quality of life in the U.S. Am J Prev Med, 54(3), 325-333. doi: 10.1016/j.amepre.2017.11.012.

13. Sharma, R. (2013). The Family and Family Structure Classification Redefined for the Current Times. J Family Med Prim Care. 2(4), 306-310. doi:10.4103/2249-4863.123774

14. Antonucci, T. C., Ajrouch, K. J., \& Manalel, J. A. (2017). Social Relations and Technology: Continuity, Context, and Change. Innov Aging. 1(3): igx029. doi:10.1093/geroni/igx029

15. Centers for Disease Control and Prevention. National Health and Nutrition Examination Survey. https://wwwn.cdc.gov/nchs/nhanes. Accessed July 12, 2017. 
16. Centers for Disease Control and Prevention. NHANES Survey Methods and Analytic Guidelines. https://wwwn.cdc.gov/nchs/nhanes/analyticguidelines.aspx. Accessed May 8, 2019.

17. U.S. Census Bureau, Population Division, Fertility \& Family Statistics Branch. (2004). Current Population Survey: Definitions and explanations. http://www.census.gov Accessed December 15, 2017.

18. CDC National Center for Health Statistics. Specifying weighting parameters. 2013. https://www.cdc.gov/nchs/tutorials/nhanes/surveydesign/weighting/intro.htm. Accessed August 11, 2017.

19. Waidmann, T., Bound, J., \& Schoenbaum, M. (1995). The illusion of failure: trends in the self-reported health of the U.S. elderly. Milbank $Q, 73,253-87$.

20. Juniper, E.F., Guyatt, G.H., Willam, A., \& Griffith, L.E. (1994). Determining a minimal important change in a disease-specific Quality of Life Questionnaire. J Clin Epidemiol, 47, 81-87.

21. Sloan, J., Symonds, T., Vargas-Chanes, D., \& Fridley, B. (2003). Practical guidelines for assessing the clinical significance of health-related quality of life changes within clinical trials. Drug Information Journal, 37, 23-31.

22. Smith D.W. (2004). The population perspective in quality of life among Americans with diabetes. Quality of Life Research, 13(8), 1391-400.

23. Ford E, S., Li, C. (2004). Metabolic syndrome and health-related quality of life among U.S. adults. Ann Epidemmiol, 18(3), 165-71.

24. Bown, D. W., Pleasants, R., Ohar, J. A., et al. (2010). Health-related quality of life and chronic obstructive pulmonary disease in North Carolina, $N$ Am J Med Sci, 2, 60-65. 
25. Hart, P. D. Meeting recommended levels of physical activity and health-related quality of life in rural adults. J Lifestyle Med, 6, 1-6

26. Dankel, S. J., Loenneke, J. P., \& Loprinzi, P. D. (2016). The WATCH (Weight Activity and Time Contributes to Health) paradigm and quality of life: the impact of overweight/obesity duration on the association between physical activity and healthrelated quality of life, Int J Clin Pract.,70(5), 409-15.

27. Ogden, C. L., Carroll, M. D., Lawman, H. G., Fryar, C. D., Kruszon-Moran, D., Kit, B. K., \& Flegal, K. M. (2016). Trends in obesity prevalence among children and adolescents in the United States, 1988-1994 Through 2013-2014. JAMA, 315(21), 2292-2299. doi:10.1001/jama.2016.6361

28. Cislaghi, B. \& Cislaghi, C. (2019). Self-rated health as a valid indicator for health-equity analyses: evidence from the Italian health interview survey. BMC Public Health. Dec;19(1), 533.

29. Office of Disease Prevention and Health Promotion. Healthy People 2020 Foundation health measure report: health-related quality of life and well-being. https://www.healthypeople.gov/sites/default/files/HRQoLWBFullReport.pdf. Accessed April 15, 2019. 


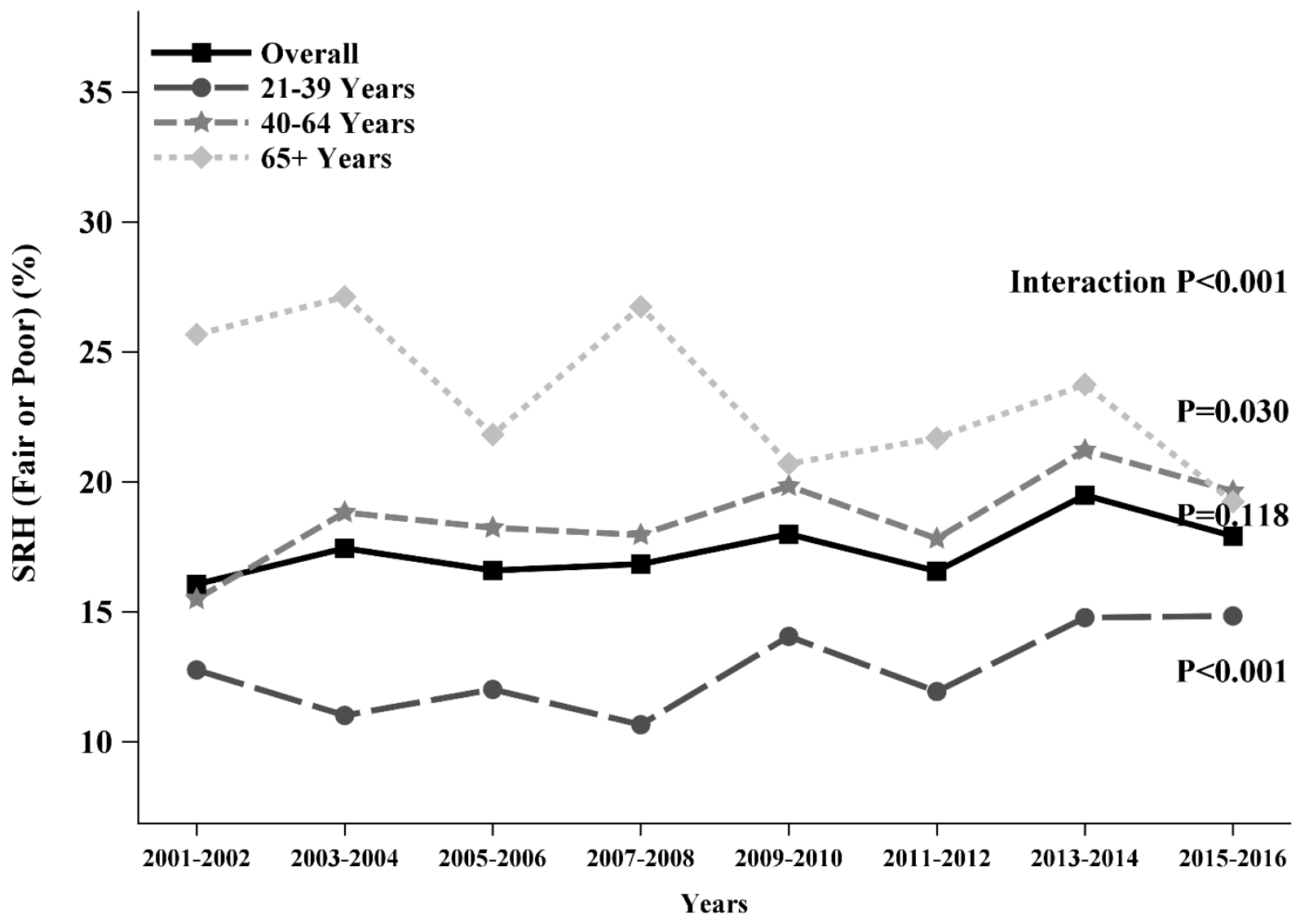

Figure 1. Trends in the prevalence of fair/poor self-reported health (SRH) by age group, NHANES 2001-02 to 2015-16 ( $\mathrm{N}=41625)$. 
Table 1. Characteristics of adult respondents in NHANES data from 2001-2016.

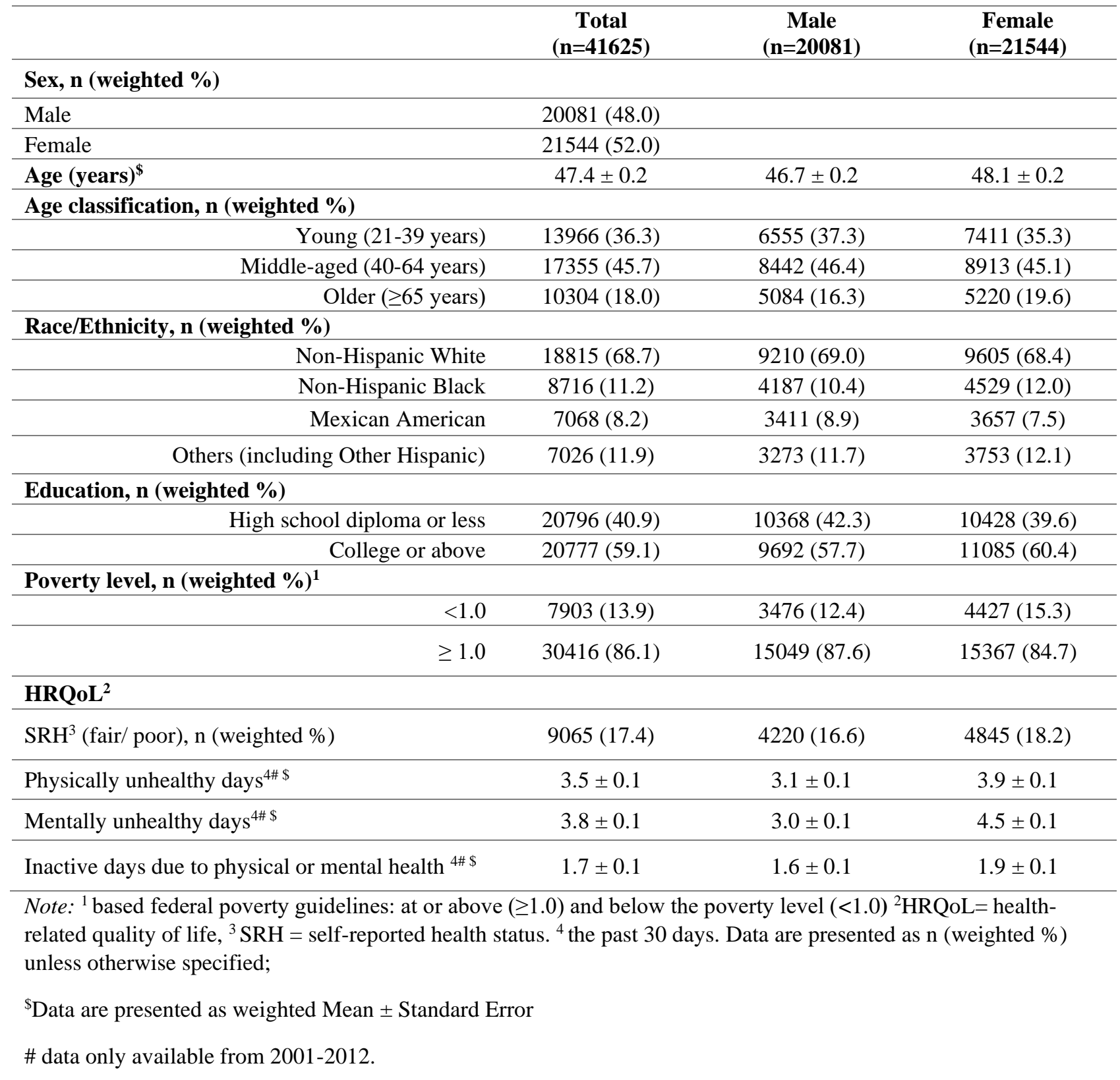


Table 2. Trends in mean or prevalence of HRQoL among NHANES respondents between 2001 and 2016 (N=41625).

Young (21-39) Middle-aged (40-64) Older ( $\geq 65)$

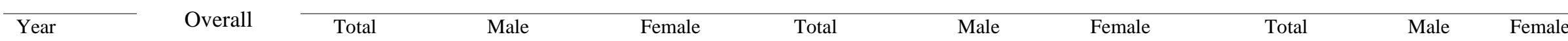

$\underline{\text { SRH (fair/poor), prevalence }(\%)(95 \% \mathrm{CI})}$

\begin{tabular}{|c|c|c|c|c|c|c|c|c|c|c|}
\hline $2001-02$ & $\begin{array}{c}16.1(15.8- \\
16.3)\end{array}$ & $\begin{array}{c}12.8(12.5 \text { - } \\
13.0)\end{array}$ & $\begin{array}{c}12.5(12.2- \\
12.9)\end{array}$ & $\begin{array}{c}13.0(12.6- \\
13.3)\end{array}$ & $\begin{array}{c}15.5(15.2- \\
15.8)\end{array}$ & $\begin{array}{c}14.0(13.5- \\
14.6)\end{array}$ & $\begin{array}{c}17.0(16.7- \\
17.3)\end{array}$ & $\begin{array}{l}25.7(25.3- \\
26.1)\end{array}$ & $\begin{array}{l}22.6(22.2- \\
22.9)\end{array}$ & $\begin{array}{c}27.9(27.3- \\
28.5)\end{array}$ \\
\hline 2003-04 & $\begin{array}{c}17.4(17.0- \\
17.8)\end{array}$ & $\begin{array}{c}11.0(10.8- \\
11.2)\end{array}$ & $\begin{array}{c}10.1(9.8- \\
10.4)\end{array}$ & $\begin{array}{c}11.9(11.6- \\
12.3)\end{array}$ & $\begin{array}{c}18.8(18.3- \\
19.3)\end{array}$ & $\begin{array}{c}18.1(17.5- \\
18.7)\end{array}$ & $\begin{array}{l}19.5(18.9- \\
20.1)\end{array}$ & $\begin{array}{c}27.1(26.4- \\
27.8)\end{array}$ & $\begin{array}{c}24.3(23.7- \\
24.9)\end{array}$ & $\begin{array}{c}29.4(28.4- \\
30.3)\end{array}$ \\
\hline $2005-06$ & $\begin{array}{c}16.6(16.3- \\
16.8)\end{array}$ & $\begin{array}{c}12.0(11.7- \\
12.3)\end{array}$ & $\begin{array}{c}13.6(13.2- \\
14.0)\end{array}$ & $\begin{array}{c}10.4(10.0- \\
10.8)\end{array}$ & $\begin{array}{c}18.2(17.8- \\
18.6)\end{array}$ & $\begin{array}{c}16.8(16.4- \\
17.2)\end{array}$ & $\begin{array}{l}19.6(18.9- \\
20.2)\end{array}$ & $\begin{array}{l}21.8(21.3- \\
22.3)\end{array}$ & $\begin{array}{l}20.7(20.1- \\
21.4)\end{array}$ & $\begin{array}{l}22.6(22.1- \\
23.1)\end{array}$ \\
\hline $2007-08$ & $\begin{array}{c}16.8(16.5 \text { - } \\
17.2)\end{array}$ & $\begin{array}{c}10.6(10.3- \\
10.9)\end{array}$ & $9.9(9.6-10.2)$ & $\begin{array}{c}11.4(11.0- \\
11.8)\end{array}$ & $\begin{array}{c}18.0(17.5- \\
18.4)\end{array}$ & $\begin{array}{c}17.3(16.6- \\
17.9)\end{array}$ & $\begin{array}{c}18.6(18.2- \\
19.0)\end{array}$ & $\begin{array}{l}26.7(26.3- \\
27.2)\end{array}$ & $\begin{array}{l}25.7(25.0- \\
26.3)\end{array}$ & $\begin{array}{l}27.6(27.0- \\
28.1)\end{array}$ \\
\hline $2009-10$ & $\begin{array}{c}18.0(17.8 \text { - } \\
18.2)\end{array}$ & $\begin{array}{c}14.0(13.7 \text { - } \\
14.3)\end{array}$ & $\begin{array}{c}12.6(12.1- \\
13.0)\end{array}$ & $\begin{array}{c}15.6(15.2- \\
16.0)\end{array}$ & $\begin{array}{l}19.8(19.6- \\
20.1)\end{array}$ & $\begin{array}{l}21.0(20.7- \\
21.4)\end{array}$ & $\begin{array}{c}18.7(18.4- \\
18.9)\end{array}$ & $\begin{array}{l}20.7(20.3- \\
21.0)\end{array}$ & $\begin{array}{c}21.2(20.7- \\
21.8)\end{array}$ & $\begin{array}{l}20.2(19.8- \\
20.7)\end{array}$ \\
\hline $2011-12$ & $\begin{array}{c}16.6(16.3- \\
16.8)\end{array}$ & $\begin{array}{c}11.9(11.6- \\
12.2)\end{array}$ & $9.7(9.3-10.1)$ & $\begin{array}{c}14.3(14.0- \\
14.6)\end{array}$ & $\begin{array}{c}17.8(17.4- \\
18.2)\end{array}$ & $\begin{array}{c}17.7(17.2- \\
18.2)\end{array}$ & $\begin{array}{c}17.9(17.6- \\
18.3)\end{array}$ & $\begin{array}{l}21.7(21.0- \\
22.3)\end{array}$ & $\begin{array}{l}21.7(20.8- \\
22.6)\end{array}$ & $\begin{array}{l}21.7(21.1- \\
22.3)\end{array}$ \\
\hline 2013-14 & $\begin{array}{c}19.5(19.2- \\
19.8)\end{array}$ & $\begin{array}{c}14.8(14.5- \\
15.0)\end{array}$ & $\begin{array}{c}15.9(15.6- \\
16.1)\end{array}$ & $\begin{array}{c}13.6(13.3- \\
14.0)\end{array}$ & $\begin{array}{l}21.2(20.7- \\
21.7)\end{array}$ & $\begin{array}{c}18.4(17.9- \\
18.8)\end{array}$ & $\begin{array}{c}23.9(23.3- \\
24.5)\end{array}$ & $\begin{array}{l}23.7(23.1- \\
24.3)\end{array}$ & $\begin{array}{l}23.7(23.0- \\
24.4)\end{array}$ & $\begin{array}{l}23.8(23.0- \\
24.6)\end{array}$ \\
\hline $2015-16$ & $\begin{array}{c}17.9(17.6- \\
18.2)\end{array}$ & $\begin{array}{c}14.8(14.5 \text { - } \\
15.2)\end{array}$ & $\begin{array}{c}14.0(13.5- \\
14.5)\end{array}$ & $\begin{array}{c}15.7(15.4- \\
16.0)\end{array}$ & $\begin{array}{l}19.6(19.3- \\
20.0)\end{array}$ & $\begin{array}{l}20.6(20.1- \\
21.0)\end{array}$ & $\begin{array}{c}18.7(18.3- \\
19.1)\end{array}$ & $\begin{array}{c}19.2(18.6- \\
19.8)\end{array}$ & $\begin{array}{c}16.8(16.2- \\
17.3)\end{array}$ & $\begin{array}{l}21.1(20.3- \\
21.9)\end{array}$ \\
\hline P for trend & 0.107 & $0.012 *$ & 0.120 & $0.026^{*}$ & 0.053 & $0.040^{*}$ & 0.266 & $0.015^{*}$ & 0.084 & $0.021 *$ \\
\hline \multicolumn{11}{|c|}{ Physically unhealthy days in past 30 days, mean $(95 \% \mathrm{CI})$} \\
\hline 2001-02 & $3.6(3.3-4.0)$ & $3.2(2.7-3.6)$ & $2.7(2.2-3.3)$ & $3.6(3.1-4.1)$ & $3.6(3.1-4.0)$ & $3.1(2.4-3.8)$ & $4.0(3.6-4.4)$ & $5.0(4.0-6.1)$ & $\begin{array}{c}4.0(3.1- \\
5.0)\end{array}$ & $5.8(4.5-7.1)$ \\
\hline 2003-04 & $3.5(3.1-4.0)$ & $2.2(1.8-2.5)$ & $1.8(1.3-2.3)$ & $2.6(1.9-3.2)$ & $4.2(3.4-5.0)$ & $4.0(3.0-5.1)$ & $4.4(3.4-5.3)$ & $4.7(3.8-5.5)$ & $\begin{array}{l}4.2(3.1- \\
5.3)\end{array}$ & $5.0(3.8-6.2)$ \\
\hline $2005-06$ & $3.3(3.1-3.6)$ & $2.1(1.8-2.4)$ & $1.7(1.3-2.1)$ & $2.5(2.1-2.9)$ & $3.8(3.3-4.3)$ & $3.2(2.7-3.7)$ & $4.4(3.3-5.5)$ & $4.6(3.7-5.5)$ & $\begin{array}{c}4.5(3.4- \\
5.6)\end{array}$ & $4.6(3.5-5.8)$ \\
\hline $2007-08$ & $3.5(3.1-3.9)$ & $2.1(1.8-2.4)$ & $1.8(1.5-2.1)$ & $2.4(1.9-2.9)$ & $4.1(3.4-4.8)$ & $3.9(3.0-4.8)$ & $4.2(3.5-5.0)$ & $4.9(4.3-5.4)$ & $\begin{array}{c}3.3(2.8- \\
3.9)\end{array}$ & $6.0(5.1-6.9)$ \\
\hline $2009-10$ & $3.7(3.3-4.1)$ & $2.6(2.3-3.0)$ & $2.1(1.7-2.4)$ & $3.2(2.7-3.8)$ & $4.2(3.5-4.8)$ & $3.7(3.0-4.4)$ & $4.6(4.0-5.2)$ & $4.6(3.8-5.5)$ & $\begin{array}{c}4.5(3.7- \\
5.2)\end{array}$ & $4.8(3.7-5.9)$ \\
\hline $2011-12$ & $3.2(2.9-3.6)$ & $1.8(1.6-2.1)$ & $1.6(1.1-2.0)$ & $2.1(1.8-2.4)$ & $3.7(3.0-4.4)$ & $3.7(3.0-4.4)$ & $3.7(3.0-4.5)$ & $4.5(3.9-5.2)$ & $\begin{array}{c}4.1(3.2- \\
5.1)\end{array}$ & $4.8(4.1-5.6)$ \\
\hline P for trend & 0.380 & $<0.001 *$ & 0.019* & 0.006* & 0.755 & 0.444 & 0.760 & 0.527 & 0.995 & 0.390 \\
\hline
\end{tabular}




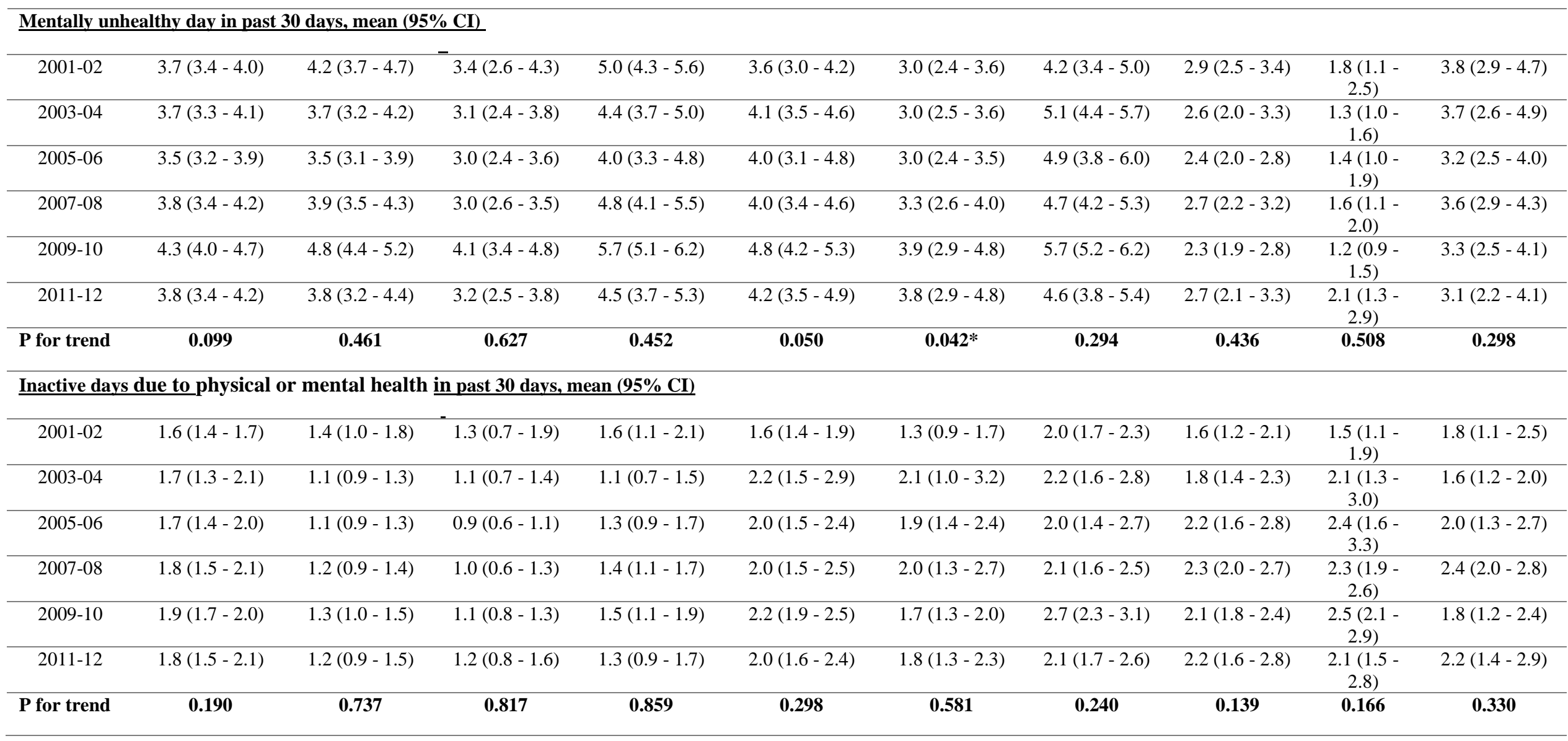

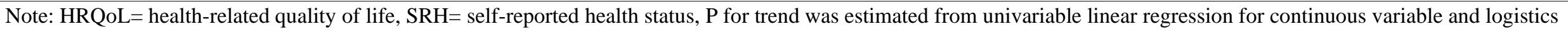
regression for binary variables in which the year was treated as continuous variable, ${ }^{*} \mathrm{p}<0.05$. 
Table 3. Adjusted biennial changes of HRQoL in NHANES respondents between 2001 and 2016 (N=41625).

Adjusted coefficient $(95 \% \mathrm{CI}, \mathrm{P}$ for trend)

\begin{tabular}{|c|c|c|c|c|}
\hline & SRH (fair/poor), $(\%)$ & $\begin{array}{l}\text { Physically unhealthy } \\
\text { days } \dagger\end{array}$ & $\begin{array}{l}\text { Mentally unhealthy } \\
\text { day } \dagger\end{array}$ & $\begin{array}{l}\text { Inactive days due to } \\
\text { physical or mental } \\
\text { health } \dagger\end{array}$ \\
\hline $\begin{array}{l}\text { Overall biennial } \\
\text { changes }\end{array}$ & $0.34(0.08-0.6,0.011 *)$ & $-0.05(-0.13-0.04,0.269)$ & $\begin{array}{c}0.06(-0.02-0.14 \\
0.124)\end{array}$ & $\begin{array}{c}0.04(-0.02-0.10 \\
0.203)\end{array}$ \\
\hline \multicolumn{5}{|l|}{ Age (years) } \\
\hline $21-39$ & $\begin{array}{c}0.49(0.22-0.76 \\
<0.001 *)\end{array}$ & $\begin{array}{c}-0.14(-0.22--0.06 \\
<0.001 *)\end{array}$ & $\begin{array}{c}0.05(-0.07-0.17 \\
0.423)\end{array}$ & $\begin{array}{c}-0.01(-0.09-0.06, \\
0.689)\end{array}$ \\
\hline $40-64$ & $0.32(-0.08-0.72,0.118)$ & $-0.01(-0.16-0.13,0.853)$ & $\begin{array}{c}0.13(-0.03-0.28 \\
0.112)\end{array}$ & $\begin{array}{c}0.03(-0.06-0.12 \\
0.512)\end{array}$ \\
\hline$\geq 65+$ & $\begin{array}{c}-0.60(-1.14--0.06 \\
0.03 *)\end{array}$ & $-0.08(-0.30-0.14,0.49)$ & $\begin{array}{c}-0.06(-0.19-0.08 \\
0.405)\end{array}$ & $\begin{array}{c}0.09(-0.04-0.22 \\
0.177)\end{array}$ \\
\hline $\begin{array}{l}\text { \#interaction terms age } \\
\text { classification*year }\end{array}$ & $<0.001^{*}$ & $<0.001^{*}$ & $<0.001^{*}$ & $<0.001 *$ \\
\hline $21-39$ & Ref & Ref & Ref & Ref \\
\hline $40-64$ & $-0.12(-0.24--0.00)$ & $0.14(0.04-0.24)$ & $0.08(-0.08-0.24)$ & $0.06(0.00-0.12)$ \\
\hline$\geq 65+$ & $-1.03(-1.63--0.43)$ & $0.09(0.01-0.17)$ & $-0.10(-0.19--0.01)$ & $0.12(0.01-0.23)$ \\
\hline \multicolumn{5}{|l|}{ Males Stratified by age } \\
\hline 21-39 & $0.46(0.04-0.88,0.03 *)$ & $-0.10(-0.21-0.000 .05)$ & $\begin{array}{c}0.06(-0.12-0.23, \\
0.536)\end{array}$ & $\begin{array}{c}-0.00(-0.11-0.10, \\
0.929)\end{array}$ \\
\hline $40-64$ & $\begin{array}{c}0.43(-0.10-0.97 \\
0.109)\end{array}$ & $0.04(-0.16-0.23,0.716)$ & $\begin{array}{c}0.16(-0.04-0.35 \\
0.115)\end{array}$ & $\begin{array}{c}0.01(-0.12-0.15 \\
0.833)\end{array}$ \\
\hline$\geq 65+$ & $\begin{array}{c}-0.31(-0.94-0.31 \\
0.322)\end{array}$ & $-0.01(-0.27-0.26,0.958)$ & $\begin{array}{c}0.02(-0.11-0.16 \\
0.736)\end{array}$ & $\begin{array}{c}0.12(-0.03-0.28 \\
0.125)\end{array}$ \\
\hline $\begin{array}{l}\text { \#interaction terms age } \\
\text { classification*year }\end{array}$ & $<0.001 *$ & $<0.001 *$ & $<0.001 *$ & $<0.001 *$ \\
\hline $21-39$ & Ref & Ref & Ref & Ref \\
\hline $40-64$ & $-0.03(-0.68-0.62)$ & $0.14(0.02-0.26)$ & $0.10(-0.08-0.28)$ & $0.03(-0.10-0.16)$ \\
\hline$\geq 65+$ & $-0.80(-1.55--0.05)$ & $0.08(0.00-0.16)$ & $-0.04(-0.00--0.08)$ & $0.13(0.01-0.25)$ \\
\hline \multicolumn{5}{|c|}{ Females stratified by age } \\
\hline 21-39 & $\begin{array}{c}0.52(0.11-0.93 \\
\left.0.013^{*}\right)\end{array}$ & $\begin{array}{c}-0.18(-0.30--0.07 \\
0.002 *)\end{array}$ & $\begin{array}{c}0.04(-0.12-0.21, \\
0.596)\end{array}$ & $\begin{array}{c}-0.02(-0.14-0.09, \\
0.685)\end{array}$ \\
\hline $40-64$ & $0.21(-0.28-0.70,0.399)$ & $-0.07(-0.23-0.10,0.421)$ & $\begin{array}{c}0.10(-0.10-0.29 \\
0.322)\end{array}$ & $\begin{array}{c}0.05(-0.06-0.15 \\
0.371)\end{array}$ \\
\hline$\geq 65+$ & $\begin{array}{c}-0.81(-1.59--0.03 \\
\left.0.042^{*}\right)\end{array}$ & $-0.13(-0.40-0.15,0.364)$ & $\begin{array}{c}-0.12(-0.35-0.12 \\
0.32)\end{array}$ & $\begin{array}{c}0.07(-0.11-0.24 \\
0.442)\end{array}$ \\
\hline $\begin{array}{l}\text { \#interaction terms age } \\
\text { classification*year }\end{array}$ & $<0.001^{*}$ & $<0.001 *$ & $<0.001 *$ & $<0.001 *$ \\
\hline $21-39$ & Ref & Ref & Ref & Ref \\
\hline $40-64$ & $-0.27(-0.53--0.01)$ & $0.12(0.01-0.23)$ & $0.05(-0.11-0.21)$ & $0.08(0.00-0.16)$ \\
\hline$\geq 65+$ & $-1.20(-2.01--0.40)$ & $0.06(0.00-0.12)$ & $-0.18(-0.33--0.03)$ & $0.11(0.01-0.21)$ \\
\hline
\end{tabular}

Note: $\dagger$ the past 30 days, $\mathrm{HRQoL}=$ health-related quality of life, $\mathrm{SRH}=$ self-reported health status. $\mathrm{P}$ for trend was estimated from multiple linear regression for continuous variable and logistic regression for binary variables in which the year was treated as continuous variable, adjusted by sex, age, race/ethnicity, education level, and poverty level. 
\# The interaction terms stratified variables, *year was added into the model to examine the effect of the interaction between stratified variables and year to investigate whether the changes over year in prevalence or mean differed between the stratified variables. 